\title{
Synthesis and characterization of amphiphilic graft copolymers of poly(1,3 dioxolane) macromonomers with styrene and methyl methacrylate
}

\author{
Hayet Bendaikha, ${ }^{1^{*}}$ Gérald Clisson, ${ }^{2}$ Abdelouahad Khoukh, ${ }^{2}$ Jeanne François, ${ }^{2}$ \\ Seghier Ould Kada'
}

${ }^{1}$ Laboratoire de Chimie Physique Macromoléculaire, Université d'Oran, 31000 Oran, Algérie ; e-mail: hbendaikha@yahoo.fr

2 Laboratoire de Physico-Chimie des Polymères, LPCP UMR 5067 Helioparc, 2 avenue du Président Angot, 64053 Pau, France.

(Received: 17 June, 2008; published: 31 January, 2009)

\begin{abstract}
Methacrylate-terminated Poly(1,3 dioxolane) (PDXL) macromonomers were synthesized by cationic ring-opening polymerization in the presence of 2hydroxypropyl methacrylate (2-HPMA) as transfer agent. Molecular weights, polydispersity index and functionality of the PDXL macromonomers were evaluated by size exclusion chromatography (SEC) and ${ }^{1} \mathrm{H}$ nuclear magnetic resonance spectroscopy ( $\left.{ }^{1} \mathrm{H}-\mathrm{NMR}\right)$. Copolymerizations of PDXL macromonomers, of different molecular weights, with styrene (St) and methyl methacrylate (MMA) were carried out using various feed molar ratios. The resulting polymers confirmed the grafting of PDXL with PS and PMMA by SEC and ${ }^{1} \mathrm{H}-\mathrm{NMR}$ Monomer reactivity ratios between the macromonomers and the comonomers were estimated from the copolymerization results. Macromonomer reactivity depends on the comonomer considered. Glass transition temperatures of the copolymers were found to decrease with an increase in the amount of PDXL in the copolymers. The values of $\mathrm{T}_{\mathrm{g}}$ depend on the composition and the size of the PDXL grafts.
\end{abstract}

\section{Introduction}

Amphiphilic block and graft copolymers consisting of hydrophilic and hydrophobic parts have been subjects of numerous studies, within which block and graft copolymers containing hydrophilic polyoxyethylene segments and other hydrophobic segments have attracted much attention, because polyoxyethylene segments are not only hydrophilic, but also nonionic and crystalline, and can complex monovalent metallic cations. Graft copolymers offer all properties of block copolymers but are usually easier to synthesize. Moreover, the branched structure leads to decreased melt viscosities which is an important advantage for processing.

Depending on the nature of their backbone and side chains, they give rise to special properties in selective solvents, at surfaces as well as in the bulk, owing to microphase separation morphologies [1]. They can be used for a wide variety of applications, such as polymeric surfactants, electrostatic charge reducers, compatibilizers in polymer blends, polymeric emulsifiers, controlled wetting ability and so on [2,3]. In order to prepare graft copolymers with well-defined structure, one can utilize the macromonomer technique (grafting through technique). Well-defined structure graft copolymers are synthesized by copolymerization of macromonomers with low molecular weight comonomers [4]. It allows the control of the polymer 
structure which is given by three parameters: (i) chain length of side chains, which can be controlled by the synthesis of the macromonomer by living polymerization; (ii) chain length of backbone, which can be controlled in a living copolymerization; (iii) average spacing of the side chains, which is determined by the molar ratio of the comonomers and the reactivity ratio of the low-molecular weight monomer. However, the distribution of spacing may not be very easy to control due to the incompatibility of the polymer backbone and the macromonomers [5]. As pointed out in recent publication reviews [6], there is a complex interplay of factors that govern the reactivities in copolymerizations involving macromonomers. When different comonomers are copolymerized with the same macromonomer, it seems that the degree of interpenetration between the macromonomer and the propagating copolymer backbone plays a major role in the measured reactivities. Nevertheless, the main properties depend on both the average composition of the systems and the microstructural distribution of the comonomer sequences along the macromolecular backbone, which is determined by the reactivity ratios of the macromonomer and the corresponding comonomer in the free radical polymerization process $[7,8,9]$.

This work deals with the preparation and characterization of new organo-soluble associative copolymers based on short hydro-soluble chains of poly(1,3 dioxolane) (PDXL). Many reports have been published on PDXL macromonomers used to form hydrogels [10-16], however, very few were on graft copolymers with PDXL branches [17]. The present paper shows several results of the synthesis of a series of methacryloyl-terminated PDXL macromonomers by cationic ring-opening polymerization. Following their characterization, these macromonomers are used for the preparation of amphiphilic graft copolymers by solution free radical copolymerization with a hydrophobic comonomer, styrene (St) and methyl methacrylate (MMA) with the aim to obtain information about the reactivity and the polymerizability of the PDXL macromonomer. Finally, their thermal properties are discussed according to the weight content of PDXL in the copolymers.

\section{Results and discussion}

In order to obtain amphiphilic graft copolymers with controlled side chain length, PDXL macromonomers were prepared with $M_{n}$ in the range of 1000-2000, bearing a methacrylic function at one of their ends, and their free radical copolymerization with vinyl and methacrylic monomers was carried out to obtain graft copolymers with hydrophobic backbone and hydrophilic side chains.

\section{Synthesis of macromonomers}

1,3 dioxolane (DXL) belongs to the class of heterocyclic monomers containing acetal functions that only polymerize cationically [18]. A specific characteristic of DXL is its lower nucleophilicity as compared to that of the acetal functions in PDXL. Thus, in competition with the propagation reaction, the active sites at the growing polymer end, i.e., cyclic dioxolenium cations will also be involved in a reaction with the acetal functions in the polymer chains [19,20]. This continuous transacetalization process results in a broadening of the molecular weight distribution and in the formation of cyclic structures [21]. It has been shown that these intermolecular transfer reactions can be applied to introduce reactive end groups on both chain ends of PDXL by the addition of a low molar mass formal as chain transfer agent during the polymerization. The synthesis of $\alpha, \omega$-dihydroxy-PDXL chains is based on the activated monomer mechanism [22]. Franta et al. have established that when DXL is 
polymerized by strong protonic acids, such as triflic acid, in the presence of a diol, the PDXL chains are essentially linear and carry end-standing $\mathrm{OH}$ functions. It has been shown that the amount of cyclic species formed is negligible, that the dispersity is on the order of 1.4 and that the molecular weight of the linear polymers is governed by the ratio of reacted monomer to transfer agent and is generally well controlled up to $10000 \mathrm{~g} / \mathrm{mol}$.

The preparation of the methacryloyl-terminated PDXL macromonomers via 'Activated Monomer' mechanism, proposed by Franta and Reibel [22, 23], using an unsaturated alcohol (2-HPMA) as a transfer agent, results in linear polymeric chains thereby preventing formation of cyclic oligomers through cationic polymerization of cyclic acetals [24-26]. They were all prepared at the same reaction conditions. The synthetic route of functionalized PDXL macromonomers is shown in Scheme1.

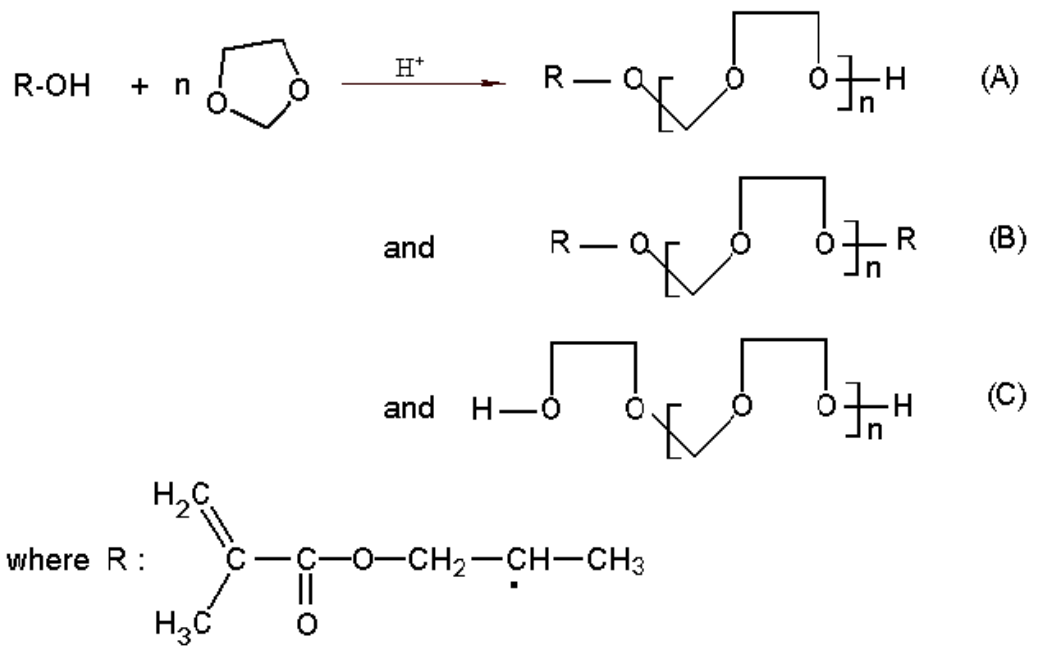

Scheme1. Structures of PDXL macromonomer species [27].

According to this mechanism, it is possible to prepare macromonomers, i.e. PDXL chains carrying polymerizable double bonds at their ends. Nevertheless, because of the transacetalization reactions, a mixture of products is obtained:

$\mathrm{A}$ is the most abundant compound; it corresponds to 50 to $60 \%$ weight wise [27]. It is a macromonomer.

B corresponds to 20 to $25 \%$ weight wise. It is a bis-macromonomer. It carries two methacryloyl functions corresponding to transacetalization of $\mathrm{R}-\mathrm{OH}$ and $\mathrm{DXL}$.

C corresponds to 20 to $25 \%$ weight wise. It carries no methacryloyl function, but two hydroxyl groups. It is a $\alpha, \omega$-dihydroxy-PDXL.

These 3 species $A, B$ and $C$ stem from scrambling reactions that are typical with cyclic acetals [27].

\section{Characterization of macromonomers}

The characterization of these materials is based on structure and molecular weight determination. For instance, the PDXL macromonomers carried at one of their ends a double bond afforded by the methacryloyl group. The latter was checked by Raman and ${ }^{1} \mathrm{H}$-NMR. spectroscopy. All macromonomers prepared displayed functionality close to unity, which makes them suitable for the synthesis of graft copolymers. 
Raman spectroscopy is used to study and analyse the structure of the macromonomers. The aim of this study is to check the formation of linear polymer chains as well as the termination with methacryloyl groups. The spectra obtained exhibit two intense Raman bands at 800 to $900 \mathrm{~cm}^{-1}$, and, 2700 to $3000 \mathrm{~cm}^{-1}$ regions, and a series of small other peaks for all samples as shown in Fig.1. The most intense band $\left(2700-3000 \mathrm{~cm}^{-1}\right)$ is assigned to the aliphatic stretching vibration of $\mathrm{CH}$ in the polyacetal chain. Symmetric $\mathrm{COCOC}$ stretching frequencies of aliphatic acetals fall in typical regions of $1115-1080 \mathrm{~cm}^{-1}$ and $870-800 \mathrm{~cm}^{-1}$ [28] and are responsible for intense Raman bands. In the low frequency region, there are three very characteristic Raman bands in the $600-550 \mathrm{~cm}^{-1}, 540-450 \mathrm{~cm}^{-1}$ and $400-320 \mathrm{~cm}^{-}$ 1 ranges which are assigned to $\mathrm{COCOC}$ deformations [28, 29]. Also, the acetals have strong multiple bands in the region of $1160-1040 \mathrm{~cm}^{-1}$ as noticed on the Raman spectra, involving the $\mathrm{C}-\mathrm{O}$ stretching modes. In addition to this, the $\mathrm{O}-\mathrm{CH}-\mathrm{O}$ group gives rise to a band at $1350-1325 \mathrm{~cm}^{-1}$ for $\mathrm{C}-\mathrm{H}$ deformation. Other intense Raman bands are observed in the region of $3000-2700 \mathrm{~cm}^{-1}$. Below $3000 \mathrm{~cm}^{-1}$, the corresponding frequencies are assigned to the aliphatic $\mathrm{C}-\mathrm{H}$ stretching modes [28]. The methoxy group is detected in the region of $2835-2780 \mathrm{~cm}^{-1}$.

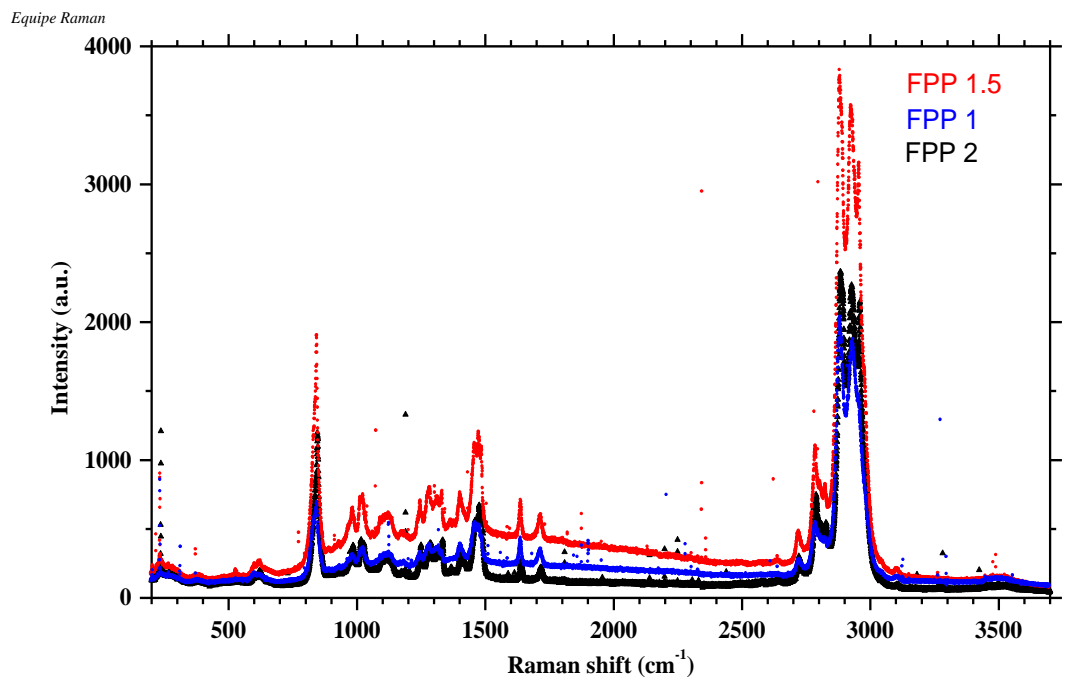

Fig. 1. Raman spectra of methacrylic-terminated PDXL macromonomers $\left(\mathrm{FPP}_{2}\right.$, $\mathrm{FPP}_{1.5}$ and $\mathrm{FPP}_{1}$ ).

As far as the presence of the methacryloyl group in the polymeric chain is important, bands have been observed at $1640 \mathrm{~cm}^{-1}$ which corresponds to $\mathrm{C}=\mathrm{C}$ bonds. The carbonyl compounds absorb strongly within $1900-1550 \mathrm{~cm}^{-1}$ region [28, 29], the spectra show a $\mathrm{C}=\mathrm{O}$ bond absorption found at $1720 \mathrm{~cm}^{-1}$. In the region of $1340-1250$ $\mathrm{cm}^{-1}$, the methacrylate bands are observed. Broad absorption is found near $3500 \mathrm{~cm}$ ${ }^{-1}$ owing to stretching of the $\mathrm{OH}$ bonds. $\mathrm{OH}$ deformation bands are found at $1400 \mathrm{~cm}$. ${ }^{1}$ and $1340 \mathrm{~cm}^{-1}$. This observation indicates that both methacrylic and $-\mathrm{OH}$ groups are present and eventually the resulting product is a mixture of the three species as shown in the scheme above. 
Typical ${ }^{1} \mathrm{H}$-NMR spectrum of PDXL macromonomer shown in Fig. 2, exhibits the expected resonance assigned to the methoxy protons $(4.77 \mathrm{ppm})$ and $\mathrm{OCH}_{2} \mathrm{CH}_{2} \mathrm{O}$ protons at $3.74 \mathrm{ppm}$. Two signals corresponding to $=\mathrm{CH}_{2}$ were observed at $(6.12$ $6.14 \mathrm{ppm})$ and (5.57 $-5.59 \mathrm{ppm})$. Therefore the spectrum confirmed the existence of methacryloyl- terminated PDXL macromonomer.

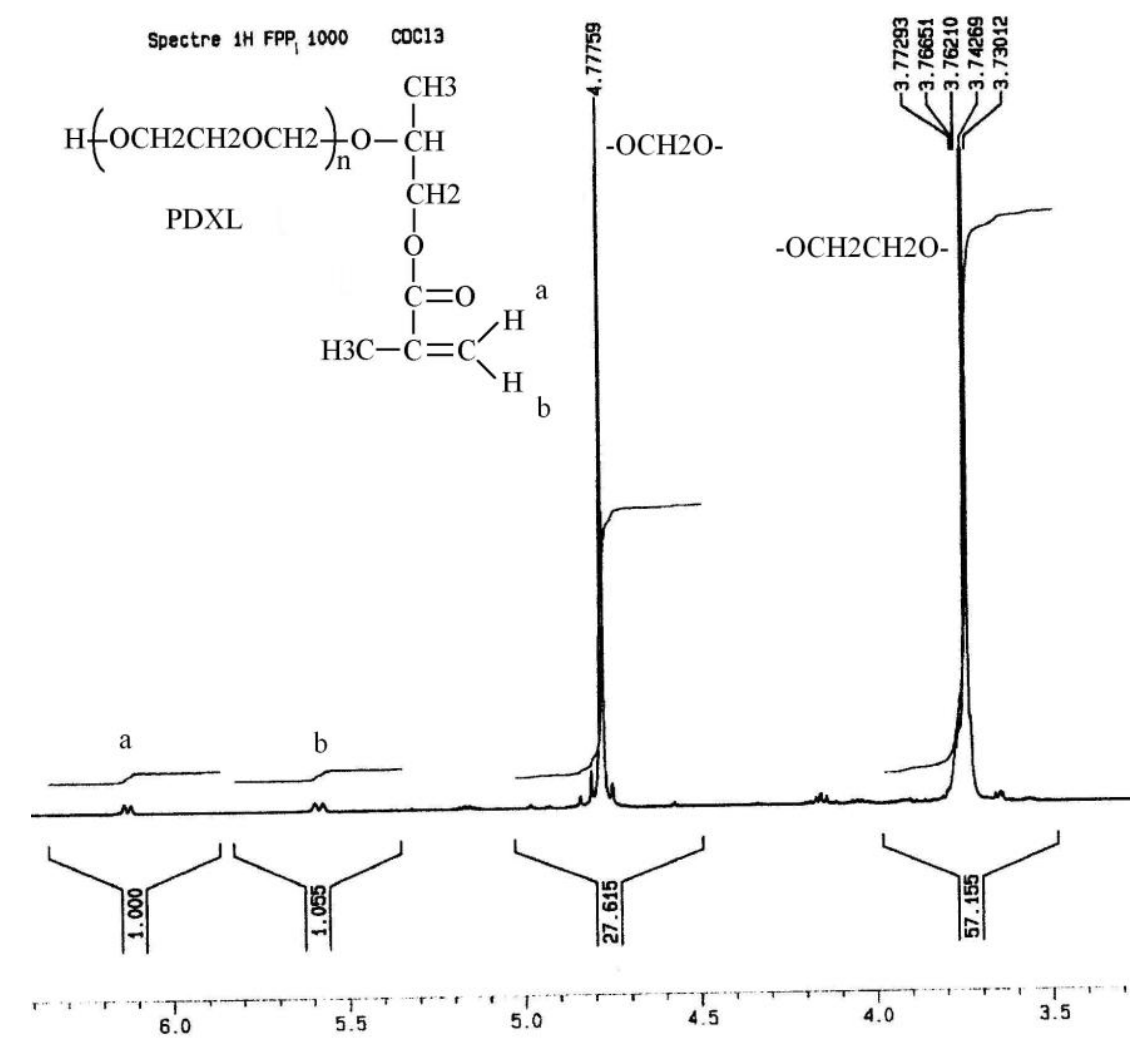

Fig. 2. ${ }^{1} \mathrm{H}-\mathrm{NMR}$ spectrum of PDXL macromonomer $\mathrm{CDCl}_{3}$ (sample $\mathrm{FPP}_{1}$ ).

Besides the structure, ${ }^{1} \mathrm{H}-\mathrm{NMR}$ enables us to determine the number-average molecular weight $\left(\mathrm{M}_{\mathrm{n}}\right)$. In the calculation of the latter, the methacryloyl end group was included. The polydispersity index, $\mathrm{M}_{\mathrm{w}} / \mathrm{M}_{\mathrm{n}}$, and the number-average molecular weight were obtained from SEC measurements. Table 1 summarizes these values. It can be seen that $M_{n}$ (SEC) and $M_{n}$ (NMR) are very close to each other for all macromonomer samples and are in agreement with the theoretical values predicted from calculations. Under our polymerization conditions, the polydispersity index is 1.6 for all samples.

Tab. 1. Characteristics of PDXL macromonomers prepared at different degrees of polymerization.

\begin{tabular}{lllcccc}
\hline Sample & $D_{p}$ & $M_{\text {nth }}$ & $M_{\text {nSEC }}$ & $M_{\text {nRMN }}$ & $\begin{array}{c}M_{w} / M_{n} \\
\text { SEC }\end{array}$ & $f^{(\text {a) }}$ \\
\hline FPP $_{1}$ & 13.5 & 1000 & 1120 & 1160 & 1.6 & 0.97 \\
FPP $_{1.5}$ & 20.25 & 1500 & 1540 & 1550 & 1.6 & 0.99 \\
FPP $_{2}$ & 27.0 & 2000 & 2040 & 2100 & 1.6 & 0.97 \\
\hline Dp:
\end{tabular}

Dp: degree of polymerization $=[\mathrm{DXL}] /[2 \mathrm{HPMA}]$

a: functionality of macromonomers (methacryloyl end groups /molecule). 


\section{Synthesis and structural characterization of copolymers}

Copolymerization of PDXL macromonomers with MMA and ST in THF solution was studied for different molar feed ratio of PDXL. The amounts of monomeric units in the copolymers were determined by elemental analysis. The results are presented in Table 2 and 3 which summarise the characteristics of the graft copolymers in terms of macromonomer feed ratio $\left(M_{2} / M_{1}\right)$ and average $M_{n}$ obtained from SEC as well as copolymer composition in weight and mole percentages which is determined from ${ }^{1} \mathrm{H}$ NMR.

Tab. 2. Characteristics of PDXL macromonomers $\left(M_{1}\right)$ copolymerized with Styrene $\left(\mathrm{M}_{2}\right)$.

$M_{1}$ in the feed $\quad M_{1}$ in the copolymer

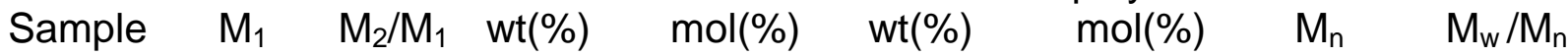

\begin{tabular}{lllllllll}
\hline $2 \mathrm{SP}_{2}$ & $\mathrm{FPP}_{2}$ & 20 & 49 & 4.76 & 40.25 & 3.37 & 9200 & 1.62 \\
$3 \mathrm{SP}_{2}$ & $\mathrm{FPP}_{2}$ & 30 & 39 & 3.22 & 30.3 & 2.21 & 8900 & 1.62 \\
$5 \mathrm{SP}_{2}$ & $\mathrm{FPP}_{2}$ & 50 & 27.7 & 1.96 & 21 & 1.3 & 7200 & 1.59 \\
& & & & & & & & \\
$\mathrm{SSP}_{1.5}$ & $\mathrm{FPP}_{1.5}$ & 20 & 41.8 & 4.76 & 34 & 3.4 & 9100 & 1.57 \\
$\mathrm{SSP}_{1.5}$ & $\mathrm{FPP}_{1.5}$ & 30 & 32.3 & 3.22 & 24 & 2.14 & 7000 & 1.61 \\
$5 \mathrm{SP}_{1.5}$ & $\mathrm{FPP}_{1.5}$ & 50 & 22.4 & 1.96 & 15.2 & 1.2 & 6700 & 1.47 \\
& & & & & & & & \\
$\mathrm{SSP}_{1}$ & $\mathrm{FPP}_{1}$ & 20 & 32.3 & 4.76 & 30 & 4.27 & 9200 & 1.78 \\
$5 \mathrm{SP}_{1}$ & $\mathrm{FPP}_{1}$ & 50 & 16 & 1.96 & 14.24 & 1.7 & 5800 & 1.58 \\
$8 \mathrm{SP}_{1}$ & $\mathrm{FPP}_{1}$ & 80 & 10.7 & 1.23 & 8.5 & 0.95 & 11900 & 1.95 \\
\hline
\end{tabular}

Tab. 3. Characteristics of PDXL macromonomers $\left(M_{1}\right)$ copolymerized with MMA $\left(\mathrm{M}_{2}\right)$.

\begin{tabular}{|c|c|c|c|c|c|c|c|c|}
\hline \multirow[b]{2}{*}{ Sample } & \multirow[b]{2}{*}{$M_{1}$} & \multirow[b]{2}{*}{$M_{2} / M_{1}$} & \multicolumn{2}{|c|}{$M_{1}$ in the feed } & \multicolumn{2}{|c|}{$M_{1}$ in the } & \multirow[b]{2}{*}{$M_{n}$ SEC } & \multirow[b]{2}{*}{$\begin{array}{c}M_{w} / M_{n} \\
\text { SEC }\end{array}$} \\
\hline & & & $\mathrm{wt}(\%)$ & $\mathrm{mol}(\%)$ & $\begin{array}{r}\text { cop } \\
\text { wt }(\%)\end{array}$ & $\begin{array}{l}\text { mer } \\
\text { mol(\%) }\end{array}$ & & \\
\hline $2 \mathrm{MP}_{2}$ & $\mathrm{FPP}_{2}$ & 20 & 50 & 4.76 & 35 & 2.6 & 21900 & 1.98 \\
\hline $3 \mathrm{MP}_{2}$ & $\mathrm{FPP}_{2}$ & 30 & 40 & 3.22 & 21 & 1.3 & 25900 & 1.57 \\
\hline $5 \mathrm{MP}_{2}$ & $\mathrm{FPP}_{2}$ & 50 & 28.6 & 1.96 & 13 & 0.7 & 87200 & 4.55 \\
\hline $2 \mathrm{MP}_{1.5}$ & $\mathrm{FPP}_{1.5}$ & 20 & 41.6 & 4.5 & 28 & 2.5 & 19800 & 1.93 \\
\hline $3 \mathrm{MP}_{1.5}$ & $\mathrm{FPP}_{1.5}$ & 30 & 33.3 & 3.22 & 22 & 1.8 & 15200 & 2.77 \\
\hline $5 \mathrm{MP}_{1.5}$ & $\mathrm{FPP}_{1.5}$ & 50 & 23 & 1.96 & 13 & 1.0 & 24700 & 1.6 \\
\hline $2 \mathrm{MP}_{1}$ & $\mathrm{FPP}_{1}$ & 20 & 33.3 & 4.76 & 26 & 3.4 & 21100 & 3.19 \\
\hline $3 \mathrm{MP}_{1}$ & $\mathrm{FPP}_{1}$ & 30 & 33.3 & 3.22 & 19 & 2.2 & 17100 & 1.97 \\
\hline $5 \mathrm{MP}_{1}$ & $\mathrm{FPP}_{1}$ & 50 & 20 & 1.96 & 10 & 1.1 & 13900 & 3.54 \\
\hline
\end{tabular}


The structure of the copolymers was well defined by ${ }^{1} \mathrm{H}-\mathrm{NMR}$ analysis. The copolymer ${ }^{1} \mathrm{H}-\mathrm{NMR}$ spectra confirm the formation of copolymers, see figures: Fig. 3 , and Fig. 4. The chemical shifts of protons of polystyrene and PDXL can be clearly distinguished.

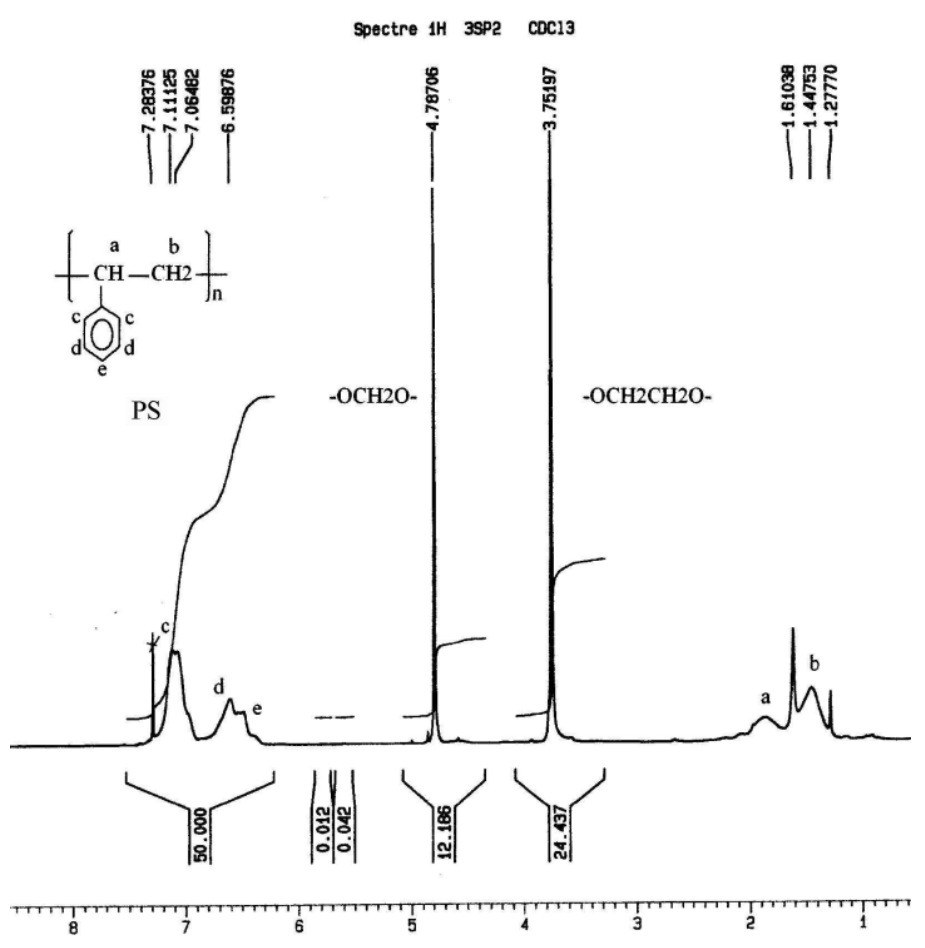

Fig. 3. ${ }^{1} \mathrm{H}-\mathrm{NMR}$ spectrum of styrene - PDXL copolymer in $\mathrm{CDCl}_{3}\left(\right.$ sample $\left.3 \mathrm{SP}_{2}\right)$.

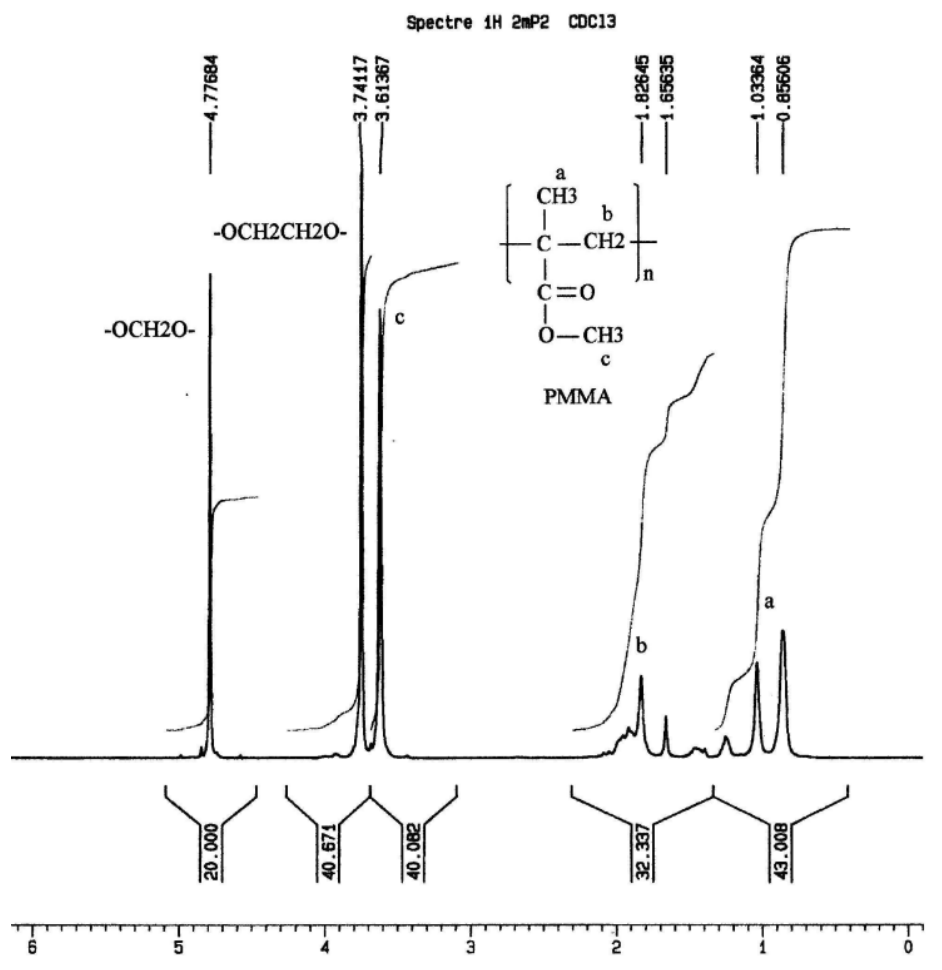

Fig. 4. ${ }^{1} \mathrm{H}-\mathrm{NMR}$ spectrum of MMA - PDXL copolymer in $\mathrm{CDCl}_{3}\left(\right.$ sample $\left.2 \mathrm{MP}_{2}\right)$. 
The following peaks are assigned for: $\mathrm{OCH}_{2} \mathrm{O}$ protons at $4.78 \mathrm{ppm}$ and $\mathrm{OCH}_{2} \mathrm{CH}_{2} \mathrm{O}$ protons at $3.75 \mathrm{ppm},\left(5 \mathrm{H}, \mathrm{C}_{6} \mathrm{H}_{5}\right)$ at $7.28,7.11$ and $7.06 \mathrm{ppm}$ as shown in Fig. 3. The spectrum of PMMA-PDXL copolymer is shown in Fig. 4 where the chemical shifts of PMMA correspond to the proton resonance as depicted in the figure: the $\mathrm{O}-\mathrm{CH}_{3}$ protons are observed at $3.61 \mathrm{ppm}$ and clear resonance assigned to the methyl group protons at $0.85-1.03 \mathrm{ppm}$, and eventually, we observe the corresponding chemical shifts for $\mathrm{OCH}_{2} \mathrm{CH}_{2} \mathrm{O}$ protons (3.74 ppm) and $\mathrm{OCH}_{2} \mathrm{O}$ protons (4.77 ppm) to confirm the incorporation of PDXL in the copolymer.

\section{Monomer reactivity ratios}

The application of the classical treatment based on linearization of the copolymerization equation of Mayo and Lewis [30] or the non-linear least-squares approach suggested by Tidwell and Mortimer [31], requires working with high macromonomer concentrations (i.e. feed compositions higher than $20-30 \%$ of macromonomer) [9].

The Mayo-Lewis equation (1), that relates the instantaneous compositions of the monomer mixture to the copolymer composition, is approximated to a simplified form (equation (2)) suggested by Jaacks [32] when working with a large excess of one of the comonomers. This is the case of copolymerization reactions between a conventional comonomer and a macromonomer of relatively high molecular weight, where using low molar concentrations of macromonomer is mandatory due to its restricted solubility and the extremely viscous media.

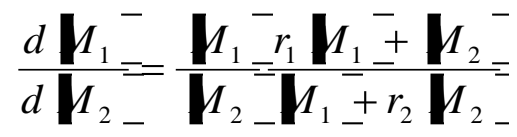

$$
\begin{aligned}
& \frac{d M_{2}^{-}}{d M_{1}=r_{2}} \frac{M_{2}}{M_{1}}
\end{aligned}
$$

Tab. 4. Monomer reactivity ratios for copolymerization of PDXL macromonomers $\left(M_{1}\right)$ with St and MMA $\left(\mathrm{M}_{2}\right)$.

\begin{tabular}{cclcccc}
\hline & $\mathbf{M}_{2}$ & \multicolumn{1}{c}{$\mathbf{M}_{\mathbf{1}}$} & & \multicolumn{2}{c}{$\mathrm{r}_{2}$} & $1 / \mathrm{r}_{2}$ \\
Sample & & macromonomer & $\mathbf{M}_{\text {nth }}$ & & & \\
\hline $\mathrm{SP}_{2}$ & $\mathrm{St}$ & $\mathrm{FPP}_{2}$ & 2000 & 0.12 & \pm 0.006 & 8.33 \\
$\mathrm{SP}_{1.5}$ & $\mathrm{St}$ & $\mathrm{FPP}_{1.5}$ & 1500 & $0.042 \pm 610^{-4}$ & 23.8 \\
$\mathrm{SP}_{1}$ & $\mathrm{St}$ & $\mathrm{FPP}_{1}$ & 1000 & $0.015 \pm 310^{-4}$ & 66.66 \\
& & & & & & \\
$\mathrm{MP}_{2}$ & $\mathrm{MMA}$ & $\mathrm{FPP}_{2}$ & 2000 & 0.02 & \pm 0.01 & 50 \\
$\mathrm{MP}_{1.5}$ & $\mathrm{MMA}$ & $\mathrm{FPP}_{1.5}$ & 1500 & 0.07 & \pm 0.02 & 14.28 \\
$\mathrm{MP}_{1}$ & $\mathrm{MMA}$ & $\mathrm{FPP}_{1}$ & 1000 & $0.018 \pm 0.01$ & 55.55 \\
\hline
\end{tabular}

According to equation (2), the copolymer composition or the frequency of branches is essentially determined by the monomer composition and the monomer reactivity ratio of the comonomer $r_{2}$ (inversely proportional to the macromonomer reactivity), under the limit condition of $\left[\mathrm{M}_{2}\right] /\left[\mathrm{M}_{1}\right]>>1$. In order to obtain reliable values, it is frequently necessary to run the copolymerization at different conversions or to carry out several 
copolymerizations with different initial monomer ratios [33]. In such cases, an integrated form of equation (2) is used:

$$
\ln \frac{h_{2}^{-}}{M_{2} \Perp}=r_{2} \ln \frac{M_{1 \pm}^{-}}{M_{1} \Perp}
$$

where $[\mathrm{Mi}] \mathrm{t} /[\mathrm{Mi}] 0$ is the ratio among the composition of monomer $\mathrm{i}$ at time $\mathrm{t}$ and the initial feed composition. A plot of $\ln \left(\left[\mathrm{M}_{2}\right]_{\mathrm{t}} /\left[\mathrm{M}_{2}\right]_{0}\right)$ versus $\ln \left(\left[\mathrm{M}_{1}\right]_{\mathrm{t}} /\left[\mathrm{M}_{1}\right]_{0}\right)$ should result in a straight line with a slope that equals to $r_{2}$ (the reactivity ratio of the comonomer).
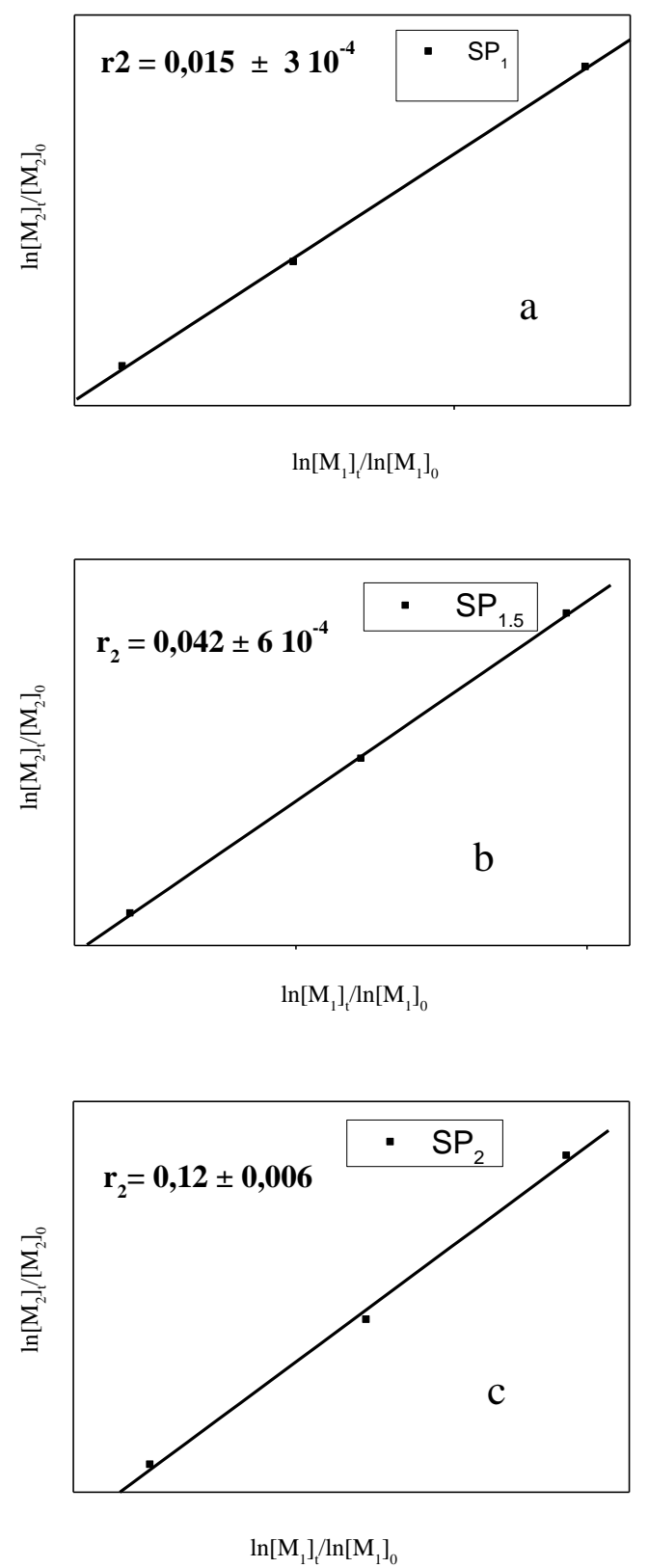

Fig. 5. Application of Jaacks' treatment to the St-PDXL copolymerization systems: (a) $\mathrm{SP}_{1}$ (b) $\mathrm{SP}_{1.5}$ (c) $\mathrm{SP}_{2}$. 
Thus, the monomer reactivity ratios between the PDXL macromonomers and the comonomers were estimated with the data in Tables 2 and 3 . We can apply equation (3) to the estimation, where $M_{1}$ and $M_{2}$ are the PDXL macromonomer and copolymer respectively. The monomer reactivity ratios are determined for macromonomers of different $\mathrm{M}_{\mathrm{n}}$ (degree of polymerization) and summarized in Table 4.
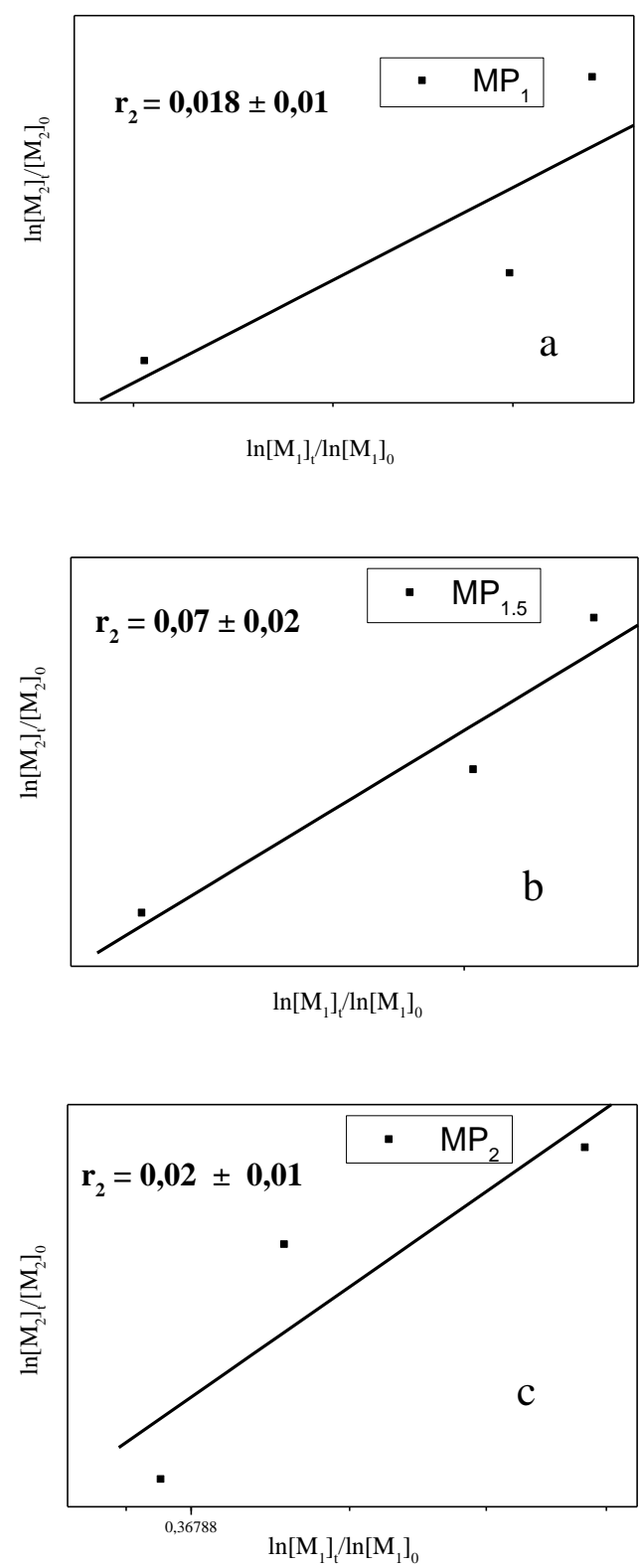

Fig. 6. Application of Jaacks' treatment to the MMA-PDXL copolymerization systems: (a) $M P_{1}$ (b) $M P_{1.5}$ (c) $M P_{2}$.

In the case of copolymerization with Styrene and MMA, the results suggest that the reactivity of the methacrylic double bond in the prepared macromonomers is not affected in their copolymerization with Styrene or MMA. This point is confirmed when analysing the inverse ratio $1 / r_{2}=k_{21} / k_{22}$, which is sometimes considered as the relative copolymerization reactivity of a macromonomer [34]. This quantity is the ratio between the crosspropagation and homopropagation rate constants of comonomer 2 , 
which is directly proportional to the reactivity of the macromonomer (1) and gives a clear idea of the relative reactivity of a growing radical ending in 2 units towards the addition of monomer 1 , in comparison to the tendency for the homopropagation. So, we have a situation where $r_{1}>1>r 2$, and it is expected that the initially formed chains should contain more macromonomers, and then more comonomer segments are added. These are only assumptions, but they give an indication about the probable composition drift of the graft copolymers obtained. On the other hand, in the case of copolymerization of poly(1,3 dioxolane) macromonomers with styrene (Fig. 5 ), the results show that $r_{2}$ increases with increasing PDXL side chain length (in terms of average $M_{n}$ ) and this leads to say that the side macromonomer chain length affect the reactivity of the comonomer. Thus, this indicates that a growing radical of macromonomer with a shorter chain length (i.e. lower $M_{n}$ ) attacks more frequently a monomer of the same nature than it does a macromonomer with a longer length (i.e. higher $M_{n}$ ), as it can be noticed from the results in Table 4. However, the $r_{2}$ values of the copolymerization with MMA (Fig. 6) give unclear dependence on the side poly (1,3 dioxolane) macromonomer chain length; this may be due to the resulting polydispersity of the copolymerization. Mentioned behaviour may be related to the reactive structure of comonomers, vinyl in the case of styrene or methacrylic in the case of MMA, in regard to the ending methacrylic double bond of macromonomers, besides the hydrophilic character of the macromonomers.

\section{Glass transition temperatures}

In the first place, the measurements of transition temperatures were performed on a conventional DSC from which the thermograms obtained show an overlapping of PS glass transition temperature and PDXL melting point signals. This has been observed for all samples.

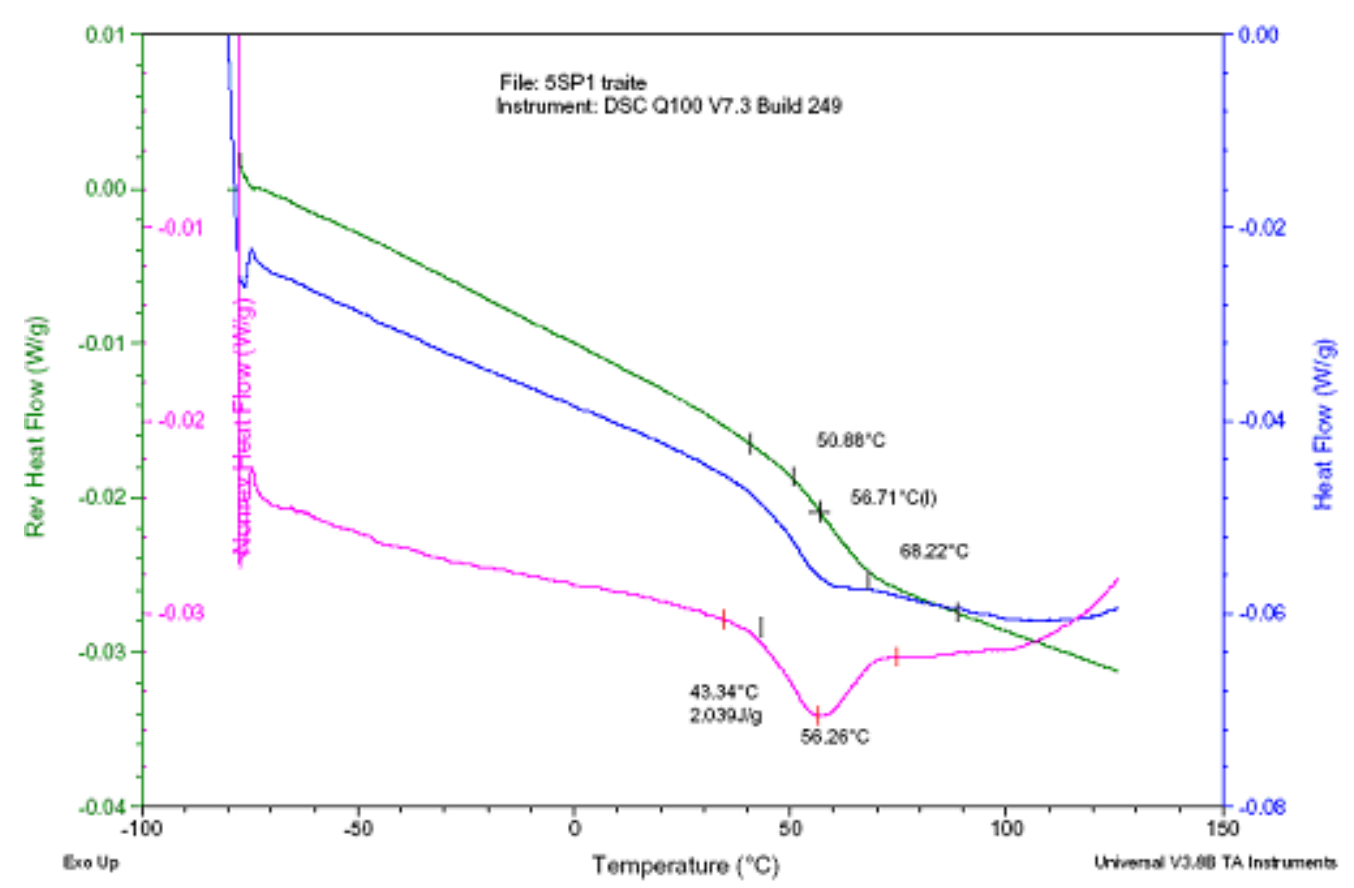

Fig. 7. MTDSC thermogram of $5 \mathrm{SP}_{1}$ copolymer at heating rate of $2{ }^{\circ} \mathrm{C} / \mathrm{min}$. 
A different approach in the characterization of these copolymers was by using a Modulated Temperature Differential Scanning Calorimeter Q100 TA instrument (MTDSC) which is an extension of conventional DSC that combines high resolution with high sensitivity by use of a sinusoidal temperature modulation superimposed on a constant temperature or linear temperature program with a small underlying average heating rate $[35,36]$. In comparison to conventional DSC, the MTDSC analysis enables the simultaneous calculations of an additional quantity, the cyclic or modulus of heat capacity, $\mathrm{Cp}\left(\mathrm{J} \mathrm{g}^{-1} \mathrm{~K}^{-1}\right)$ [35]:

$$
C p=\frac{A_{H F}}{A_{T} \omega}
$$

where $A_{H F}$ is the amplitude of the cyclic heat flow $\left(\mathrm{Wg}^{-1}\right)$ and $A_{T \omega}$ is the amplitude of cyclic heating rate, with $A_{T}$ the temperature modulation amplitude $(K), \omega$ the modulation angular frequency $(2 \pi / p)$ and $p$ is the modulation period (s) [35]. In fact, the MTDSC splits the overlapped signals into two distinct temperatures, melting temperature of the hydrophilic grafts and glass transition temperature of the hydrophobic backbone as can be noticed in Fig. 7 in which melting temperature appears to be $56.26{ }^{\circ} \mathrm{C}$ which is closer to the glass transition temperature with a value of $56.71^{\circ} \mathrm{C}$.

Tab. 5. Transition temperatures of styrene-PDXL copolymers obtained by thermal analysis (DSC).

\begin{tabular}{lcc}
\hline Sample & $\begin{array}{c}\mathrm{PDXL} \text { content } \\
\text { wt }(\%)\end{array}$ & $\begin{array}{c}\mathrm{Tg} \\
\left({ }^{\circ} \mathrm{C}\right)\end{array}$ \\
\hline $8 \mathrm{SP}_{1}$ & 8.5 & 74.89 \\
$5 \mathrm{SP}_{1}$ & 14.24 & 56.71 \\
$5 \mathrm{SP}_{1.5}$ & 15.2 & 55.90 \\
$5 \mathrm{SP}_{2}$ & 21 & 67.39 \\
$3 \mathrm{SP}_{2}$ & 30.3 & 44.80 \\
$2 \mathrm{SP}_{1.5}$ & 34 & 26.65 \\
$\mathrm{SP}_{2}$ & 40.25 & 40.60 \\
\hline
\end{tabular}

Tab. 6. Transition temperatures of MMA-PDXL copolymers obtained by thermal analysis (DSC).

\begin{tabular}{lcc}
\hline Sample & $\begin{array}{c}\text { PDXL content } \\
\text { wt }(\%)\end{array}$ & $\begin{array}{c}\mathrm{T}_{\mathrm{g}} \\
\left({ }^{\circ} \mathrm{C}\right)\end{array}$ \\
\hline $5 \mathrm{MP}_{1}$ & 10 & 105.45 \\
$5 \mathrm{MP}_{1.5}$ & 13 & 82.78 \\
$3 \mathrm{MP}_{2}$ & 21 & 65.76 \\
$3 \mathrm{MP}_{1.5}$ & 22 & 75.50 \\
$2 \mathrm{MP}_{1}$ & 26 & 70.13 \\
\hline
\end{tabular}

From these measurements, $T_{g}$ was taken at the midpoint of the transition region. The results obtained are shown in Tables 5 and 6 for copolymers with styrene and MMA respectively. Then, a plot of the copolymers $T_{g}$ has been constructed against PDXL content in order to study the effect of the latter on $T_{g}$ 's. As it can be noticed in the Fig. $8, T_{g}$ of the copolymers decreases exponentially with increasing PDXL content and this may be due to the decrease in the intermolecular interactions between the 
molecular chains and can be associated with higher mobility and flexibility of the polymeric chains when PDXL is incorporated in the copolymers. The results clearly indicate that $T_{g}$ values of the copolymers depend on the composition of comonomers and decrease with increasing PDXL content in the obtained copolymers.
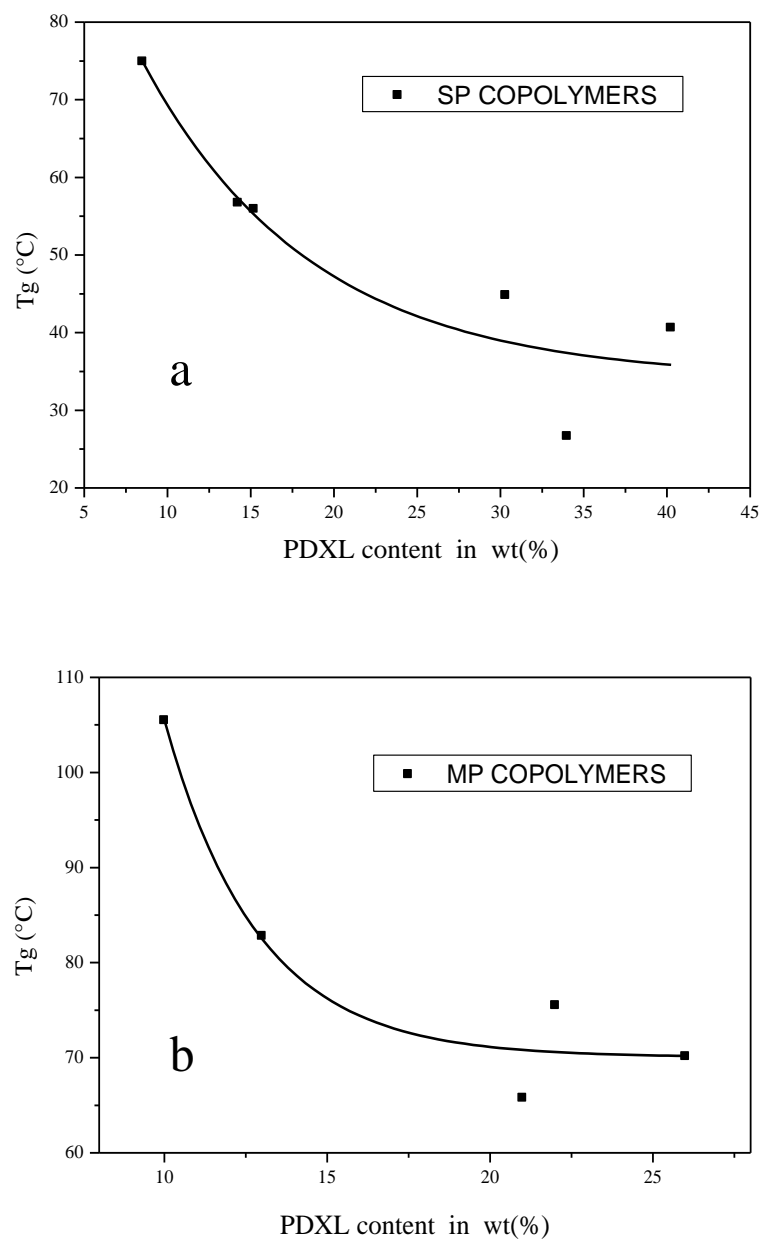

Fig. 8. Glass transition temperatures vs. PDXL macromonomer content for copolymer systems: (a) styrene-PDXL copolymers; (b) MMA-PDXL copolymers.

\section{Conclusions}

Methacrylate-terminated PDXL macromonomers were copolymerized with St and MMA using different feed molar ratios. Both feed molar ratio and the size of the graft influence the composition of the copolymers. The macromonomer reactivity estimation suggests that the length of the PDXL side chains does affect the reactivity of the methacrylic double bond of the macromonomer when copolymerized with St. However, in the case of copolymerization with MMA, there is no dependence on the graft size. Finally, from DSC measurements, the values of $T_{g}$ depend on the composition and the size of the PDXL grafts. In all copolymers, the increase in amount of the incorporated PDXL macromonomer results in a substantial decease in glass transition. 


\section{Experimental part}

\section{Materials}

The monomer 1,3 dioxolane (DXL) and 2-hydroxypropyl methacrylate (2-HPMA) of commercial grades were purchased from Acros. DXL was kept under $\mathrm{KOH}$ for two to three days to remove any peroxide and stabiliser traces and then purified by distillation over $\mathrm{CaH}_{2}$ prior to polymerization. Trifluoromethanesulfonic acid (triflic acid, Aldrich) was used as received. Commercially available styrene (St) and MMA (Prolabo) were purified by distillation over $\mathrm{CaH}_{2}$ at reduced pressure. $\mathrm{CH}_{2} \mathrm{Cl}_{2}$ and THF commercially available from Prolabo were purified by conventional methods [15, 37]. 2,2-Azobisisobutyronitrile (AIBN) recrystallized from methanol was used. All chemicals were kept over molecular sieve before use.

\section{Macromonomer Synthesis}

Methacrylate-terminated PDXL macromonomers were synthesized by Cationic ringopening polymerization which was carried out in $10 \mathrm{ml}$ dichloromethane with triflic acid as initiator at room temperature under nitrogen for $24 \mathrm{~h}$, in the presence of 2hydroxypropyl methacrylate (2-HPMA) as transfer agent. $20 \mathrm{ml}$ of DXL monomer was added. The feed molar ratios [DXL]/ [2-HPMA] as well as the molecular characteristics of the obtained macromonomers are reported in Table 1. The amount of the acid used was $20 \mu \mathrm{l}$. After reaction, the resulting solution was poured into THF. Then, the product was purified by re-precipitation from THF solution with a large excess of hexane and the obtained polymer was dried under vacuum at room temperature. The yield was checked by gravimetric determination and found to be about $80 \%$.

\section{Copolymer Synthesis}

PDXL macromonomers of different molecular weights were copolymerized with St and MMA in THF at $60{ }^{\circ} \mathrm{C}$ in the presence of $2,2^{\prime}$-azobisisobutyronitrile, AIBN, $(1 \%$, based on the total weight of the monomers) as initiator, under a nitrogen atmosphere, using different feed molar fractions of macromonomers.

Tab. 7. Copolymerization of PDXL macromonomers $\left(M_{1}\right)$ with styrene $\left(M_{2}\right)$.

\begin{tabular}{ccccccccccc}
\hline Sample & $\mathrm{M}_{1}$ & & \multicolumn{2}{c}{$\mathrm{PDXL}$} & & $\begin{array}{c}\text { Styrene } \\
(\mathrm{mol})\end{array}$ & $(\mathrm{ml})$ & $\begin{array}{c}\text { AIBN } \\
(\mathrm{g})\end{array}$ & $\begin{array}{c}\text { THF } \\
(\mathrm{ml})\end{array}$ & $\begin{array}{c}\text { Conc. } \\
(\mathrm{mol} / \mathrm{l})\end{array}$ \\
\hline $2 \mathrm{SP}_{2}$ & $\mathrm{FPP}_{2}$ & 20 & 3.49 & $17.4510^{-4}$ & 3.64 & $3.4910^{-2}$ & 4 & 0.07 & 60 & 0.610 \\
$3 \mathrm{SP}_{2}$ & $\mathrm{FPP}_{2}$ & 30 & 2.32 & $11.610^{-4}$ & 3.64 & $3.4910^{-2}$ & 4 & 0.06 & 60 & 0.601 \\
$5 \mathrm{SP}_{2}$ & $\mathrm{FPP}_{2}$ & 50 & 1.4 & $6.9810^{-4}$ & 3.64 & $3.4910^{-2}$ & 4 & 0.05 & 60 & 0.593 \\
\hline $2 \mathrm{SP}_{1.5}$ & $\mathrm{FPP}_{1.5}$ & 20 & 2.62 & $17.4510^{-4}$ & 3.64 & $3.4910^{-2}$ & 4 & 0.06 & 60 & 0.610 \\
$3 \mathrm{SP}_{1.5}$ & $\mathrm{FPP}_{1.5}$ & 30 & 1.74 & $11.610^{-4}$ & 3.64 & $3.4910^{-2}$ & 4 & 0.06 & 60 & 0.601 \\
$5 \mathrm{SP}_{1.5}$ & $\mathrm{FPP}_{1.5}$ & 50 & 1.05 & $6.9810^{-4}$ & 3.64 & $3.4910^{-2}$ & 4 & 0.05 & 60 & 0.593 \\
\hline $2 \mathrm{SP}_{1}$ & $\mathrm{FPP}_{1}$ & 20 & 1.74 & $17.4510^{-4}$ & 3.64 & $3.4910^{-2}$ & 4 & 0.06 & 60 & 0.610 \\
$5 \mathrm{SP}_{1}$ & $\mathrm{FPP}_{1}$ & 50 & 0.7 & $6.9810^{-4}$ & 3.64 & $3.4910^{-2}$ & 4 & 0.05 & 60 & 0.593 \\
$8 \mathrm{SP}_{1}$ & $\mathrm{FPP}_{1}$ & 80 & 0.436 & $4.3610^{-4}$ & 3.64 & $3.4910^{-2}$ & 4 & 0.05 & 60 & 0.589 \\
\hline
\end{tabular}


The total monomer concentration was $610^{-1} \mathrm{M}$ in all cases. The copolymerization product was diluted with THF and then added dropwise to a large excess of methanol to remove unreacted PDXL macromonomers [38, 39]. The polymers were finally dried over vacuum at $40^{\circ} \mathrm{C}$ to constant weight. The yields of all reactions were $70-$ $90 \%$. Tables 7 and 8 summarize the amount of all reagents used for the copolymerizations.

Tab. 8. Copolymerization of PDXL macromonomers $\left(M_{1}\right)$ with MMA $\left(M_{2}\right)$.

\begin{tabular}{|c|c|c|c|c|c|c|c|c|c|c|}
\hline Sample & $M_{1}$ & $M_{2} / M_{1}$ & (g) & $\begin{array}{l}\mathrm{DXL} \\
(\mathrm{mol})\end{array}$ & (g) & $\begin{array}{l}\text { MMA } \\
\text { (mol) }\end{array}$ & & $\begin{array}{c}\text { AIBN } \\
(\mathrm{g})\end{array}$ & $\begin{array}{l}\text { THF } \\
\text { (ml) }\end{array}$ & $\begin{array}{l}\text { Conc. } \\
\text { (mol//) }\end{array}$ \\
\hline $2 \mathrm{MP}_{2}$ & $\mathrm{FPP}_{2}$ & 20 & 3.74 & $18.710^{-4}$ & 3.744 & $3.7410^{-2}$ & 4 & 0.08 & 65 & 0.604 \\
\hline $3 \mathrm{MP}_{2}$ & $\mathrm{FPP}_{2}$ & 30 & 2 & $10 \quad 10^{-4}$ & 3.00 & $3.0010^{-2}$ & 3.2 & 0.05 & 50 & 0.620 \\
\hline $5 \mathrm{MP}_{2}$ & $\mathrm{FPP}_{2}$ & 50 & 1.5 & $7.4810^{-4}$ & 3.744 & $3.7410^{-2}$ & 4 & 0.05 & 60 & 0.636 \\
\hline $2 \mathrm{MP}_{1.5}$ & $\mathrm{FPP}_{1.5}$ & 20 & 2 & $13.310^{-4}$ & 2.8 & $2.8010^{-2}$ & 3 & 0.05 & 25 & 1.00 \\
\hline $3 \mathrm{MP}_{1.5}$ & $\mathrm{FPP}_{1.5}$ & 30 & 1.87 & $12.510^{-4}$ & 3.744 & $3.740^{-2}$ & 4 & 0.06 & 60 & 0.644 \\
\hline $5 \mathrm{MP}_{1.5}$ & $\mathrm{FPP}_{1.5}$ & 50 & 1.12 & $7.4810^{-4}$ & 3.744 & $3.7410^{-2}$ & 4 & 0.05 & 60 & 0.636 \\
\hline $2 \mathrm{MP}_{1}$ & $\mathrm{FPP}_{1}$ & 20 & 2 & $2010^{-4}$ & 4.00 & $410^{-2}$ & 4.3 & 0.06 & 50 & 0.840 \\
\hline $3 \mathrm{MP}_{1}$ & $\mathrm{FPP}_{1}$ & 30 & 1.25 & $12.510^{-4}$ & 3.744 & $3.7410^{-2}$ & 4 & 0.05 & 64 & 0.604 \\
\hline $5 \mathrm{MP}_{1}$ & $\mathrm{FPP}_{1}$ & 50 & 0.75 & $7.4810^{-4}$ & 3.744 & $3.7410^{-2}$ & 4 & 0.05 & 60 & 0.636 \\
\hline
\end{tabular}

\section{Characterization}

Raman spectroscopy was used to study and analyse the structure of the macromonomers. Number-average molecular weights $\left(M_{n}\right)$ and polydispersity indices $\left(\mathrm{M}_{\mathrm{w}} / \mathrm{M}_{\mathrm{n}}\right)$ were determined by Size Exclusion Chromatography (SEC) and ${ }^{1} \mathrm{H}-\mathrm{NMR}$. SEC Measurements were performed at $40^{\circ} \mathrm{C}$ on a Waters 2690 instrument equipped with UV detector (Waters 996 PDA) coupled with a Differential Refractometer (ERC $7515 \mathrm{~A})$ and four Styragel columns $\left(10^{6}, 10^{5}, 500\right.$ and $\left.50^{\circ} \mathrm{A}\right)$. THF was employed as a solvent with $1 \mathrm{ml} / \mathrm{min}$ flow rate. Polystyrene standard samples were used for calibration. ${ }^{1} \mathrm{H}-\mathrm{NMR}$ spectra were recorded on Advance Bruker spectrometer. Deuterated chloroform was used as solvent. DSC measurements were performed on a Modulated Temperature Differential Scanning Calorimeter Q100 TA instrument, under nitrogen at $50 \mathrm{ml} / \mathrm{min}$. The samples were hermetically sealed in aluminium pans and they were subjected to a heating program as follows:

- ramp of $5^{\circ} \mathrm{C} / \mathrm{min}$ to $80^{\circ} \mathrm{C}$

- a ramp of $2^{\circ} \mathrm{C} / \mathrm{min}$ to $-60^{\circ} \mathrm{C}$

- then an isothermal for $5 \mathrm{~min}$

- finally a ramp of $2{ }^{\circ} \mathrm{C} / \mathrm{min}$ to $80^{\circ} \mathrm{C}$.

Acknowledgements

The authors would like to thank Pr. D. Bormann (CNRS Orléans, France) for his advice and technical assistance with Raman spectroscopy.

\section{References}

[1] Xiea, H-Q.; Xieb, D. Prog. Polym. Sci., 1999, 24, 275.

[2] Fernandez-Garcia, M.; Luis de la Fuente, J.; Cerrada, M.L.; Madruga, E.L. Polymer, 2002, 43, 3173.

[3] Hou S.S.; Kuo P.L. Polymer, 2001, 42, 2387. 
[4] Schulz, G. O.; Milkovich, R. J. Appl. Polym. Sci., 1982, 27, 4773.

[5] Roos, S.G.; Muller, A.H. E. Macromolecules, 1999, 32, 8331.

[6] Meijs, F.; Rizzardo, E. J.Macromol. Sci, Rev. Macromol. Chem.Phys., 1990, 33(C30), 305.

[7] Eguiburu, J.L.; Fernandez-Berridi, M.J.; San Roman, J. Polymer, 1996, 37 (16), 3615.

[8] Larraz, E.; Elvira, C.; Gallardo, A.; San Roman, J. Polymer, 2005, 46, 2040.

[9] Eguiburu, J.L.; Fernandez-Berridi, M.J. Polymer, 1996, 37 (16), 3615.

[10] Adriaensens, P.; Storme, L. ; Carleer, R.; Gelan, J.; Du Prez, F.E. Macromolecules, 2002, 35, 3965.

[11] Naraghi, K.; Sahli, N.; Belbachir, M.; Franta, E.; Lutz P.J. Polym. Inter., 2002, 51, 912.

[12] Peng, D.Y.; Zhang, T.; Ding, X.; Zheng, Z. Journal of Applied Polymer Science, 2002, 83, 1678.

[13] Reguieg, F.; Sahli, N.; Belbachir, M.; Lutz, P.J. Journal of Applied Polymer Science, 2006, 99, 3147.

[14] Juan, D.; Yuxing, P.; Zhang, T.T.; Xiaobin, D.; Zhaohui, Z. Journal of Applied Polymer Science, 2002, 83, 1678.

[15] Lutz, P.J. Polymer Bulletin, 2006.

[16] Du, J.; Peng, Y.; Ding, X. Colloid Polym Sci, 2003, 281, 90.

[17] Reibel, L.C.; Durand, C.P.; Franta, E. Can. J. Chem./Rev. Can. Chim., 1985, 63, 264.

[18] Plesch, P.H.; Westermann, P.H. Polymer, 1969,10, 105.

[19] Penczek, S.; Kubisa, P.; Matyjaszewski, K. Adv. Polym. Sci., 1980, 37, SpringerVerlag; Berlin.

[20] Ivin, K.J.; Saegusa, T. Ring opening Polymerization, Elsevier Publishers: Amsterdam, 1984, Vol.1.

[21] Matyjaszewski,, K.; Zielinski M.; Kubisa, P.; Slomkowski, S.; Chojnowski, J.; Penczek, S. Makromol. Chem., 1980, 181, 1469.

[22] Franta, E.; Kubisa, P.; Refai, J.; Ould Kada, S.; Reibel, L. Makromol. Chem. Makromol. Symp., 1988, 13/14, 127.

[23] Franta, E.; Refai, J.; Durand, C.; Reibel, L. Makromol. Chem. Makromol. Symp., 1990, 32, 169.

[24] Koji, I.; Xiang, S.X. Polymer, 1999, 40, 3251.

[25] Xie, H_Q.; Pan, S-B.; Guo, J-S. European Polymer Journal, 2003, 39, 715.

[26] Penczek, S.; Kubisa, P. Polym. Sci. Ed. by G. Allen And J.C.Bevinton, Pergamon Press., 1989, 3, 787.

[27] Franta, E.; Kubisa, P.; Ould Kada, S.; Reibel, L. Makromol. Chem. Makromol., Symp., 1992, 60, 145.

[28] Daimay, L-V."The Handbook of IR and Raman Characteristic Frequencies of Organic Molecules" United Kingdom Ed. by Academic Press Limited, London.

[29] Norman, B. Colthup."Introduction to Infrared and Raman Spectroscopy", $3^{\text {rd }}$ Edition. AP Limited. London.

[30] Mayo, F.R.; Lewis, F.M. J. Am. Chem. Soc., 1944, 66, 1594.

[31] Tidwell, P.W.; Mortimer, B.A. J. Polym. Sci. A, 1965, 3, 269.

[32] Jaacks, V. Makromol Chem, 1972, 161.

[33] Larraz, E.; Elvira, C.; Gallardo, A.; San Roma'n, J. Polymer, 2005, 46, 2040.

[34] Ito, K. Progr. Polym. Sci., 1998, 23 (4), 581.

[35] Dreezen, G.; Groeninckx, G.; Swier, S.; Van Mele, B. Polymer, 2001, 42, 1449.

[36] Reading, M.; Elliot, D.; Hill, V.L. J. Thermal Anal., 1993, 40, 949. 
[37] Goethals, E.J.; Makromol Chem Makromol Symp, 1991, 48, 427.

[38] Srivastava, A.K.; Pandey, P. European Polymer Journal, 2002, 38, 1709.

[39] Ishizu, K.; Furukawa, T. Polymer, 2001, 42, 7233. 